\title{
Levenberg-Marquardt Algorithm Combined with Bipolar Sigmoid Function to Measure Open Unemployment Rate in Indonesia
}

\author{
Anjar Wanto ${ }^{1}$, Irfan Sudahri Damanik ${ }^{1}$, Indra Gunawan ${ }^{1}$, Eka Irawan $^{1}$, Heru Satria Tambunan ${ }^{1}$, \\ Sumarno Sumarno ${ }^{1}$, Zulaini Masruro Nasution ${ }^{1}$ \\ ${ }^{I}$ STIKOM Tunas Bangsa, Sudirman street Blok A Number 1, 2, 3 Pematangsiantar, North Sumatra - Indonesia \\ \{anjarwanto@amiktunasbangsa.ac.id,irfansudahri@amiktunasbangsa.ac.id,indra@amiktunasbangsa.ac.id, \\ eka.irawan@amiktunasbangsa.ac.id,heru@amiktunasbangsa.ac.id,sumarno@amiktunasbangsa.ac.id, \\ zulaini@amiktunasbangsa.ac.id\}
}

Keywords: Levenberg-Marquardt, Combined, Sigmoid, Bipolar, Unemployment.

\begin{abstract}
The purpose of this research is to see how much open unemployment rate according to the highest education completed in the country of Indonesia for subsequent years through predictions used on the basis of existing data, which later as input for the government so that the government can make better policies to suppress the unemployment rate. This research uses artificial neural network application using a combination of Levenberg-Marquardt Algorithm with bipolar sigmoid function. Open unemployment data according to the highest education is sourced from the National Labor Force Survey of the Republic of Indonesia, 2013-2017 in each semester. The data processing consists of two stages where the first phase of pattern recognition and the second stage is predicted. Pattern recognition and prediction use different data from the same process that uses data training and data testing. Data Training year 2013-2015 with target of 2016, while data testing year 2014-2016 with target year 2017. Architectural model used there are five, among others 6-2-5-2, 6-5-6$2,6-5-8-2,6-5-10-2$ and 6-8-12-2. From the 5 models it can be concluded that the best model is 6-5-10-2 with epoch of 13 iterations, MSE in February 0.0109696004, MSE in August 0.0233797200. While the accuracy rate in February and August is the same, that is equal to $88 \%$.
\end{abstract}

\section{INTRODUCTION}

Unemployment is a term for people who do not work at all, looking for work, working less than two days a week or someone trying to get a decent job. Unemployment is largely due to the fact that the number of the labor force or job seekers is not proportional to the amount of available employment that is able to absorb it. Unemployment is often a problem in the economy, because, with unemployment, people's productivity and income will be reduced so that it can cause poverty and other social problems. Open Unemployment Rate is the percentage of unemployment to the total labor force.

Unemployment in Indonesia includes issues that are still difficult to overcome by the government. Many factors affect the unemployment rate, one of which is inflation, financial crisis to low levels of community education (Tesfaselassie and Wolters
2017) (Carrillo-Tudela, Graber, and Waelde 2017). Therefore, the role of government is needed in tackling the problem of unemployment. Open unemployment data in Indonesia according to the highest education completed can be seen in the following table:

Table 1: Open Unemployment According to Completed Higher Education

\begin{tabular}{|c|l|r|r|r|r|r|}
\hline \multirow{2}{*}{$\mathrm{Nu}$} & \multicolumn{1}{|c|}{$\begin{array}{c}\text { Highest } \\
\text { Education } \\
\text { Completed }\end{array}$} & \multicolumn{2}{|c|}{2013} & $\ldots$ & \multicolumn{2}{|c|}{2017} \\
\cline { 3 - 7 } & February & August & $\ldots$ & February & August \\
\hline 1 & Never School & 112.435 & 81.432 & $\ldots$ & 92.331 & 62.984 \\
\hline 2 & $\begin{array}{l}\text { Hasn't finished } \\
\text { primary school }\end{array}$ & 523.400 & 489.152 & $\ldots$ & 546.897 & 404.435 \\
\hline 3 & Primary school & 1.421 .873 & 1.347 .555 & $\ldots$ & 1.292 .234 & 904.561 \\
\hline 4 & Junior high school & 1.821 .429 & 1.689 .643 & $\ldots$ & 1.281 .240 & 1.274 .417 \\
\hline 5 & $\begin{array}{l}\text { Senior High } \\
\text { School } \\
\text { General }\end{array}$ & 1.874 .799 & 1.925 .660 & $\ldots$ & 1.552 .894 & 1.910 .829 \\
\hline 6 & $\begin{array}{l}\text { SHS / Vocational } \\
\text { School }\end{array}$ & 864.649 & 1.258 .201 & $\ldots$ & 1.383 .022 & 1.621 .402 \\
\hline 7 & $\begin{array}{l}\text { Academy / } \\
\text { Diploma }\end{array}$ & 197.270 & 185.103 & $\ldots$ & 249.705 & 242.937 \\
\hline 8 & University & 425.042 & 434.185 & $\ldots$ & 606.939 & 618.758 \\
\hline
\end{tabular}




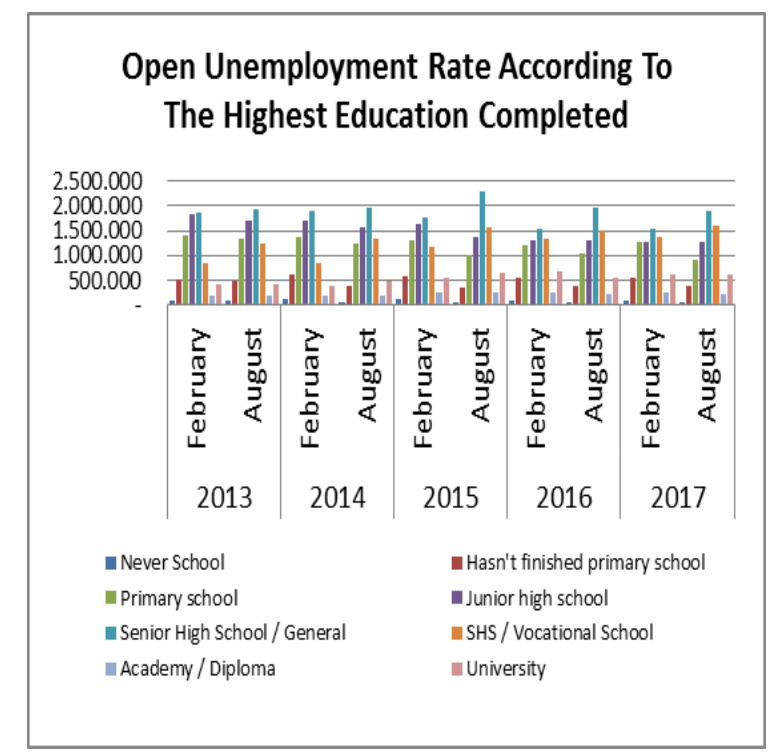

Figure 1: Open Unemployment According to Completed Higher Education

One way to suppress open unemployment by the highest education completed is to forecast the unemployment rate for subsequent years. Forecasting results will be used as a barometer for the Government to determine the policy as early as possible, by applying appropriate measures considered in overcoming unemployment. However, the forecasting process is not easy, it takes the basic model and time series data of those problems, which is generally complicated by the estimation of inaccurate accuracy, requiring more advanced techniques (Hrasko, Pacheco, and Krohling 2015).

Therefore, forecasting techniques using the Levenberg-Marquardt Algorithm combined with bipolar sigmoid function. The Levenberg-Marquardt algorithm is closer to the matrix that usually exists in the optimization method. This reduces algorithm complexity significantly (Sarabakha et al. 2017). This algorithm is a powerful algorithm capable of approaching and simplifying problems resulting in faster and less complex convergence than standard gradient descent or even backpropagation JST methods. The Levenberg-Marquardt algorithm is widely favored as a forecasting algorithm, because of its superior performance with the use of more consequent parameters (Castillo et al. 2013) (Salimifard and Safavi 2013), and has many successful implementations (Khanesar and Kayacan 2013).

In this research, the Levenberg-Marquardt algorithm will be combined with bipolar sigmoid function. The bipolar sigmoid function is almost the same as the binary sigmoid function, only the output of this function has a range between 1 to -1 . The bipolar sigmoid function is often used to predict time series data whose value is up and down (unstable), therefore we could readily analyze the situation of using bipolar sigmoid activation function (Yunong Zhang and Ke Chen 2008) (Zhang, Zhang, and Im 2017).

\section{RUDIMENTARY}

\subsection{Artificial Intelligence}

Artificial Intelligence is one area that is quite reliable in solving problems such as prediction (forecasting) (A. Wanto et al. 2017). AI is a very important discipline and it includes a number of well recognized and mature areas including Neural Network (Chiroma et al. 2014) (Hakim, Sari, and Herawan 2014) (Lasisi, Ghazali, and Herawan 2014). Artificial Intelligence (AI) is a general term that implies the use of a computer to model intelligent behavior with minimal human intervention. AI is generally accepted as having started with the invention of robots. The term derives from the Czech word robota, meaning biosynthetic machines used as forced labor (Hamet and Tremblay 2017). AI is a field of research based on the premise that intelligent thought can be regarded as a form of computation - one that can be formalized and ultimately mechanized. To achieve this, however, two major issues need to be addressed. The first issue is knowledge representation, and the second is knowledge manipulation (Sumijan et al. 2016).

\subsection{Artificial Neural Networks (ANN)}

Artificial Neural Network (ANN) is one of the studies of Artificial Intelligence and is a new computing technology in the field of computer science research. Neural networks mostly used for problem-solving in pattern recognition, data analysis, control and clustering (Adnan et al. 2017). Initially ANN were developed in the field of artificial intelligence and were first introduced for image recognition. The central concept was inspired by knowledge of the nervous system, especially the human brain with its closely connected neurons (Ehret et al. 2015). Artificial neural network (ANN) is one of the methods that is suitable to deal with the internal relations of complex model because of its highly nonlinear, large amounts of data parallel processing, high robustness, and fault tolerance (Wang et al. 2017) (Anjar Wanto et al. 2017). 


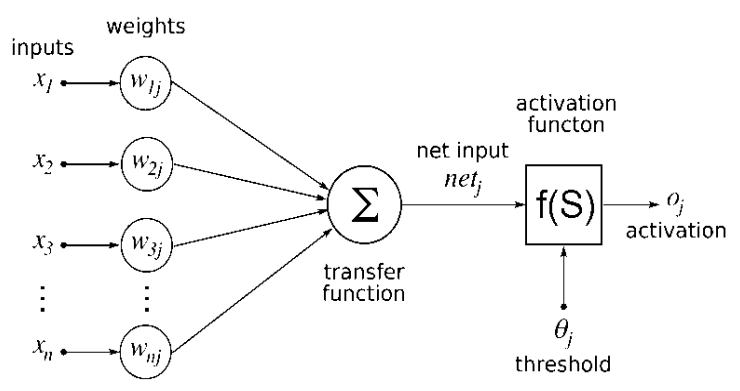

Figure 2: Artificial Neural Networks

The schematic representation of artificial neural network. It consists of: (1) input layer (independent variables), (2) hidden layers and, (3) the output layer (dependent variable) (Parveen, Zaidi, and Danish 2017) (Putra Siregar and Wanto 2017).

\subsection{Levenberg Marquardt Algorithm}

In engineering and scientific computing, the Levenberg-Marquardt algorithm (LMA or just LM) is used to solve non-linear least squares problems. The algorithm was first published in 1944 by Kenneth Levenberg (Levenberg 1944) and in 1963 by Donald Marquardt (Marquardt 1963). It is well known that the LM method has quadratic convergence as the Newton method if the Jacobian is Lipschitz continuous and nonsingular at some solutions. However, the condition on the nonsingularity of the Jacobian is very strong. (Yamashita and Fukushima 2001) (Fan and Pan 2009) (Fan and Yuan 2005) Showed that if the LM parameter is chosen properly, then the LM method preserves the quadratic convergence under the local error bound condition, which is weaker than nonsingularity.

In this paper, we propose an LM algorithm to predict the time series data to be combined with the bipolar sigmoid activation function, to see how well the accuracy and quality of these algorithms are in forecasting the times series data

\subsection{Sigmoid Bipolar Function}

The activation function is used to build training networks on artificial neural networks. Determining the optimal activation function of artificial neural networks is important because it is directly related to the success rate obtained. But, unfortunately, there is no way to determine it analytically, the optimal activation function is generally determined by testing or adjustment. This paper discusses a simpler and more effective approach for optimal activation functionality. In this approach, which can be referred to as a trained activation function, the activation function is trained for each particular neuron. The training process is based on the training dataset, which consists of the number of inputs of each neuron in the hidden layer and the desired output. In this way, different activation functions are generated for each neuron in the hidden layer (Ertugrul 2018).

In artificial neural networks, the activation function used must meet several conditions, namely: continuous, can be derived and is a function that does not go down. One of the activation functions that meet the characteristics of artificial neural networks is the function of bipolar sigmoid function. The derivative of this activation function is required by the update weight rule, due to the condition of the differentialization that requires the requirements (Mishra et al. 2017). This paper uses bipolar sigmoid Function because time series data to be processed up and down value (unstable), therefore we could readily analyze the situation of using bipolar sigmoid activation function.

\section{RESULT AND DISCUSSION}

\subsection{Data Collection}

Data to be processed is unemployment data in Indonesia according to the highest the education year 2013-2017. Data source from the National Labor Force Survey and Indonesian Central Bureau of Statistics. The data can be seen in table 1 in the previous discussion.

\subsection{Data Training and Testing}

The dataset year 2013-2015 is used as training with target 2016. While the dataset year 2014-2016 used as testing with a target of 2017 .

\subsection{Normalization Data}

The data will be normalized using the following formula.

$$
x^{\prime}=\frac{0.8(x-a)}{b-a}+0.1
$$

Table 2: Normalization of training data

\begin{tabular}{|c|l|c|c|c|c|c|}
\hline \multirow{2}{*}{ Nu. } & \multirow{2}{*}{$\begin{array}{c}\text { Highest Education } \\
\text { Completed }\end{array}$} & \multicolumn{2}{|c|}{2013} & $\ldots$ & \multicolumn{2}{c|}{2017} \\
\cline { 3 - 7 } & Feb & Aug & $\ldots$ & Feb & Aug \\
\hline 1 & Never School & 0,1205 & 0,1093 & $\ldots$ & 0,1139 & 0,1014 \\
\hline 2 & $\begin{array}{l}\text { Hasn't finished primary } \\
\text { school }\end{array}$ & 0,2683 & 0,2559 & $\ldots$ & 0,2805 & 0,2181 \\
\hline
\end{tabular}




\begin{tabular}{|c|c|c|c|c|c|c|}
\hline \multirow{2}{*}{ Nu. } & \multirow{2}{*}{$\begin{array}{l}\text { Highest Education } \\
\text { Completed }\end{array}$} & \multicolumn{2}{|c|}{2013} & \multirow{2}{*}{$\begin{array}{l}\cdots \\
\cdots\end{array}$} & \multicolumn{2}{|c|}{2017} \\
\hline & & Feb & Aug & & Feb & Aug \\
\hline 3 & Primary school & 0,5914 & 0,5646 & $\ldots$ & 0,5184 & 0,4525 \\
\hline 4 & Junior high school & 0,7351 & 0,6877 & ... & 0,5525 & 0,5456 \\
\hline 5 & $\begin{array}{l}\text { Senior High School / } \\
\text { General }\end{array}$ & 0,7543 & 0,7726 & ... & 0,6363 & 0,7815 \\
\hline 6 & SHS / Vocational School & 0,3910 & 0,5325 & ... & 0,5649 & 0,6269 \\
\hline 7 & Academy / Diploma & 0,1510 & 0,1466 & $\ldots$ & 0,1697 & 0,1590 \\
\hline 8 & University & 0,2329 & 0,2362 & $\ldots$ & 0,3301 & 0,2840 \\
\hline
\end{tabular}

Table 3: Normalization of testing data

\begin{tabular}{|c|l|c|c|c|c|c|}
\hline \multirow{2}{*}{ Nu. } & \multirow{2}{*}{$\begin{array}{c}\text { Highest Education } \\
\text { Completed }\end{array}$} & \multicolumn{2}{|c|}{$\mathbf{2 0 1 3}$} & $\ldots$ & \multicolumn{2}{c|}{2017} \\
\cline { 3 - 7 } & \multirow{2}{*}{1} & Fever School & Aug & $\ldots$ & Feb & Aug \\
\hline 2 & $\begin{array}{l}\text { Hasn't finished primary } \\
\text { school }\end{array}$ & 0,1282 & 0,1070 & $\ldots$ & 0,1132 & 0,1027 \\
\hline 3 & Primary school & 0,5745 & 0,5222 & $\ldots$ & 0,5448 & 0,4053 \\
\hline 4 & Junior high school & 0,6890 & 0,6435 & $\ldots$ & 0,5408 & 0,5383 \\
\hline 5 & $\begin{array}{l}\text { Senior High School / } \\
\text { General }\end{array}$ & 0,7610 & 0,7859 & $\ldots$ & 0,6385 & 0,7672 \\
\hline 6 & SHS / Vocational School & 0,3848 & 0,5592 & $\ldots$ & 0,5774 & 0,6631 \\
\hline 7 & Academy / Diploma & 0,1502 & 0,1496 & $\ldots$ & 0,1698 & 0,1674 \\
\hline 8 & University & 0,2233 & 0,2581 & $\ldots$ & 0,2983 & 0,3025 \\
\hline
\end{tabular}

\subsection{Analysis And Results}

\subsubsection{Analysis}

This research uses 5 architectural models with 2 hidden and 2 outputs, among others: 6-2-5-2, 6-5-62, 6-5-8-2, 6-5-10-2 and 6-8-12-2. Training and test parameters using Target Minimum Error $=0.001$ 0.05, Maximum Epoch $=1000$, and Learning Rate $=$ 0.001. The Levenberg-Marquardt (trainlm) algorithm will be combined with the bipolar sigmoid activation function (tansig). Broadly speaking, the analysis of this combination will be applied using Matlab 2011. The program listing can be seen as follows:

$>$ net=newff( $\operatorname{minmax}(P),[$ Hidden,Target],\{'tansig','pureli $n^{\prime}$, 'tansig'\},'trainlm');

$>$ net.IW $\{1,1\}$;

$>$ net.b $\{1\}$;

$>$ net. $L W\{2,1\}$;

$>$ net.b $\{2\}$;

$>$ net. $L W\{3,2\}$;

$>$ net.trainparam.epochs $=1000$;

$>$ net.trainparam. $L R=0.001$;

$>$ net.trainParam.goal $=0.001$;

$>$ net.trainParam.show $=1000$;

$\gg$ net.b $\{3\}$;

\section{> net=train $($ net $, P, T)$}

\subsubsection{Results}

Overall, the best results of the 5 network architecture models used are 6-5-10-2, with the accuracy of output in semester 1 (February) at $88 \%$ and in the 2nd semester (August) also equal $88 \%$. Actually, the architecture model 6-5-8-2 produces $100 \%$ accuracy in semester 1 (February), but in the 2nd semester (August) its accuracy is low ie $75 \%$. So we chose 65-10-2 as the best model, with consideration of stable accuracy.

For more details can be seen in the following picture:

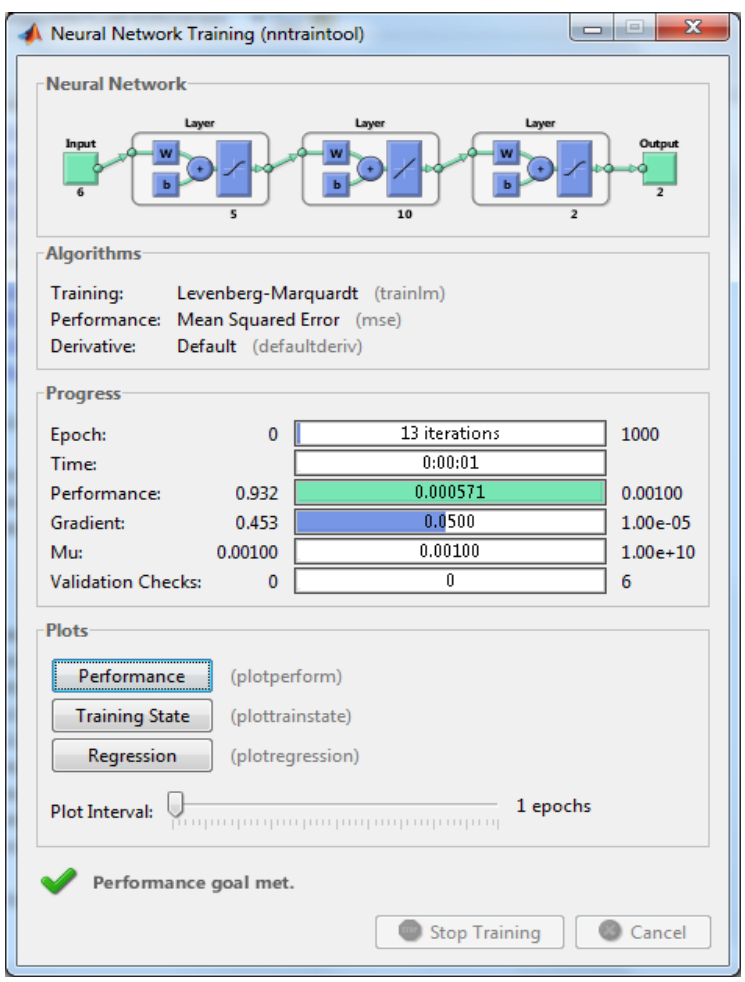

Figure 3: Training with architecture 6-5-10-2

Comparison of standard gradient descent training functions with gradient descent with momentum and adaptive LR can be seen in the following table:

Table 4: Results Levenberg-Marquardt + Bipolar

\begin{tabular}{|c|c|c|c|c|c|}
\hline \multirow{2}{*}{ Arsitektur } & \multirow{2}{*}{ Epoch } & \multicolumn{2}{|c|}{ MSE } & \multicolumn{2}{c|}{ Akurasi } \\
\cline { 3 - 6 } & & Feb & Agu & Feb & Agu \\
\hline $6-2-5-2$ & 14 & 0,0022588499 & 0,0065650062 & $63 \%$ & $75 \%$ \\
\hline $6-5-6-2$ & 6 & 0,0126063807 & 0,0680858800 & $75 \%$ & $63 \%$ \\
\hline $6-5-8-2$ & 6 & 0,0004848094 & 0,0043782187 & $100 \%$ & $75 \%$ \\
\hline $6-5-10-2$ & 13 & 0,0109696004 & 0,0233797200 & $88 \%$ & $88 \%$ \\
\hline
\end{tabular}




\begin{tabular}{|c|c|c|c|c|c|}
\hline \multirow{2}{*}{ Arsitektur } & \multirow{2}{*}{ Epoch } & \multicolumn{2}{|c|}{ MSE } & \multicolumn{2}{c|}{ Akurasi } \\
\cline { 3 - 6 } & & Feb & Agu & Feb & Agu \\
\hline $6-8-12-2$ & 9 & 0,1704704039 & 0,1267147790 & $75 \%$ & $75 \%$ \\
\hline
\end{tabular}

Comparison of each Epoch from the 5 architecture models can be seen in the following figure:

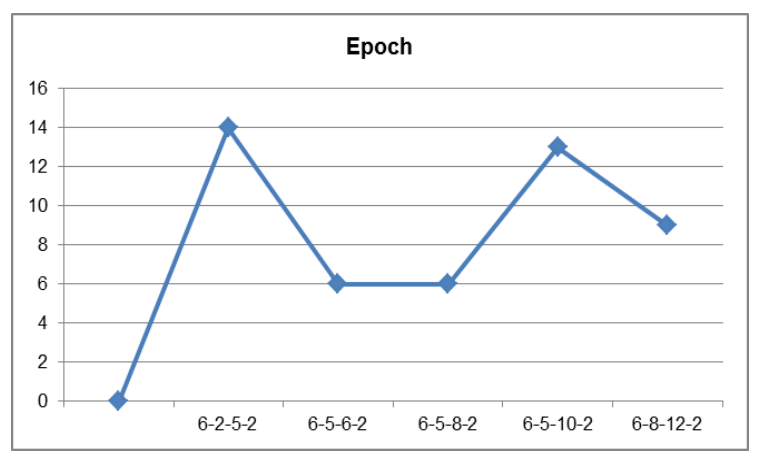

Figure 4: Comparison of Epoch

Comparison of MSE from the 5 architectural models can be seen in the following figure:

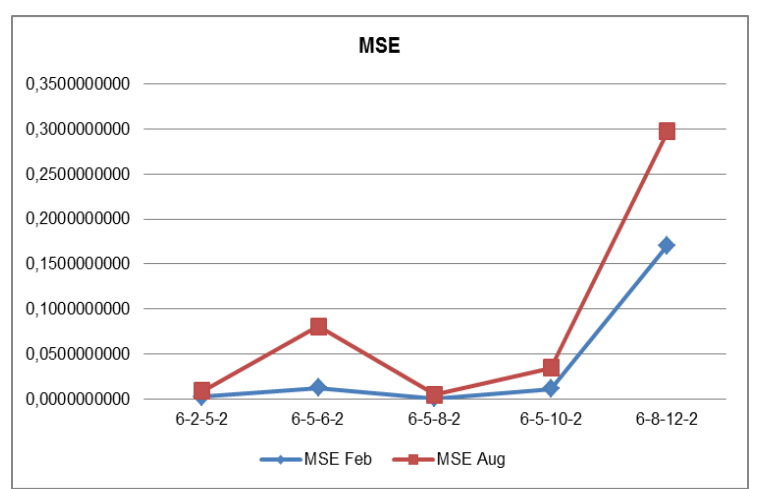

Figure 5: Comparison of MSE

Perbandingan tingkat akurasi dari ke 5 model arsitektur dapat dilihat pada gambar berikut:

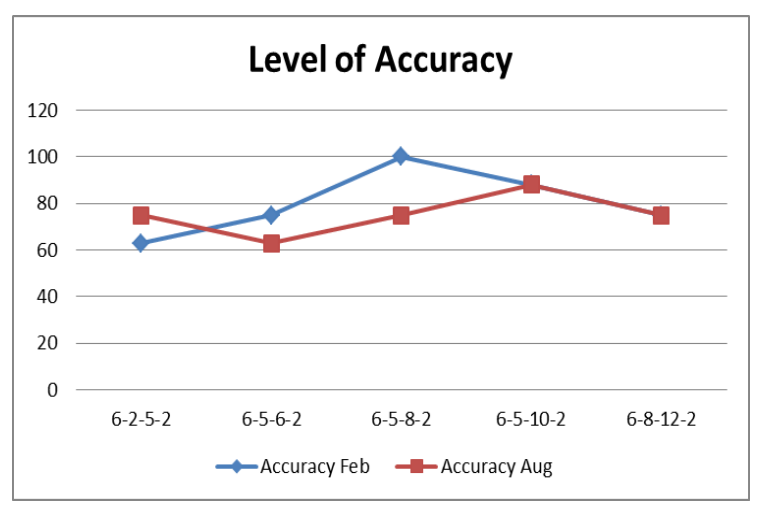

Figure 6: Comparison of Accuracy
The overall comparison (Epoch, MSE, and Accuracy) of the 5 architectural models can be seen in the following figure:

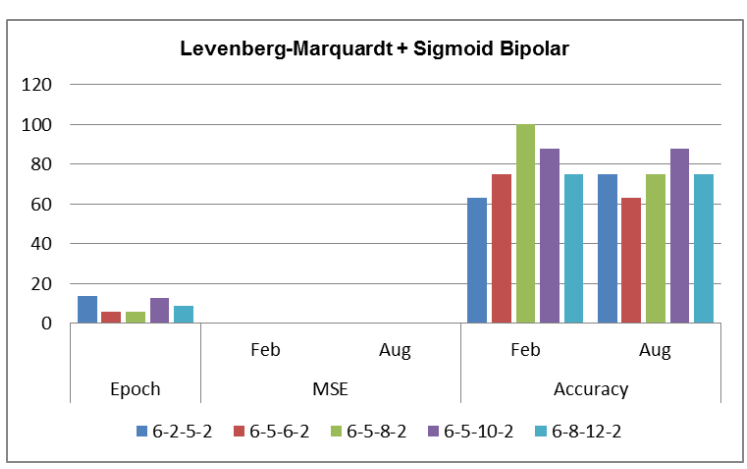

Figure 7: Comparison of Epoch, MSE, and Accuracy

From forecasting calculations using the Levenberg-Marquardt algorithm combined with the bipolar sigmoid activation function, it will show the results of open unemployment forecasting in Indonesia according to the highest education completed as follows (2018-2020):

Table 5: Results of Open unemployment forecast by highest education completed (2018-2020)

\begin{tabular}{|r|r|r|r|r|r|}
\hline \multicolumn{2}{|c|}{2018} & \multicolumn{2}{c|}{2019} & \multicolumn{2}{c|}{2020} \\
\hline February & \multicolumn{1}{|c|}{ August } & February & August & February & August \\
\hline 119.343 & 68.989 & 117.641 & 97.529 & 138.002 & 125.775 \\
\hline 449.646 & 353.327 & 311.097 & 183.148 & 179.698 & 145.338 \\
\hline 1.181 .392 & 771.864 & 787.267 & 597.450 & 418.745 & 374.848 \\
\hline 1.185 .781 & 1.079 .299 & 810.060 & 783.436 & 416.299 & 398.325 \\
\hline 1.173 .308 & 1.601 .315 & 727.889 & 1.075 .727 & 394.290 & 537.841 \\
\hline 1.141 .894 & 1.363 .174 & 741.489 & 881.314 & 403.950 & 458.484 \\
\hline 232.986 & 218.665 & 203.260 & 169.740 & 157.444 & 141.670 \\
\hline 521.019 & 532.568 & 392.693 & 421.999 & 296.837 & 276.906 \\
\hline
\end{tabular}

\section{CONCLUSIONS}

From the previous explanation, it can be concluded as follows:

1. The accuracy, MSE and Epoch levels of the Levenberg-Marquardt Algorithm combined with bipolar sigmoid depend on the architectural model used.

2. Determination of the parameters of optimum network can only be done based on the learning process and the determination of the 
error so that the length of research time can't be determined with certainty.

3. The number of iterations can't be determined by the size of the desired pattern recognition accuracy but is determined by the parameters of the network used, the initial conditions of the network and the characteristics of the input data.

\section{REFERENCES}

Adnan, J. et al. 2017. "Multilayer Perceptron Based Activation Function On Heart Abnormality Activity." Journal of Fundamental and Applied Sciences ISSN 9(3S):417-32.

Carrillo-Tudela, Carlos, Michael Graber, and Klaus Waelde. 2017. "Unemployment and Vacancy Dynamics with Imperfect Financial Markets." Labour Economics 1-33. Retrieved (http://dx.doi.org/10.1016/j.labeco.2017.04.00 5).

Castillo, Oscar, Juan R. Castro, Patricia Melin, and Antonio Rodriguez-diaz. 2013. "Universal Approximation of a Class of Interval Type-2 Fuzzy Neural Networks in Nonlinear Identification." Advances in Fuzzy Systems 116. Retrieved (http://www.ncbi.nlm.nih.gov/pubmed/213838 39).

Chiroma, Haruna, Sameem Abdulkareem, Adamu I. Abubakar, and Tutut Herawan. 2014. "Kernel Functions for the Support Vector Machine: Comparing Performances on Crude Oil Price Data." Advances in Intelligent Systems and Computing 287:273-81.

Ehret, Anita, David Hochstuhl, Daniel Gianola, and Georg Thaller. 2015. "Application of Neural Networks with Nack-Propagation to GenomeEnabled Prediction of Complex Traits in Holstein-Friesian and German Fleckvieh Cattle." Genetics Selection Evolution 47(22):1-9. Retrieved (http://www.gsejournal.org/content/47/1/22).

Ertugrul, Omer Faruk. 2018. "A Novel Type of Activation Function in Artificial Neural Networks: Trained Activation Function." Neural Networks 99:1-22. Retrieved (https://doi.org/10.1016/j.neunet.2018.01.007).

Fan, Jin Yan and Ya Xiang Yuan. 2005. "On the Quadratic Convergence of the LevenbergMarquardt Method without Nonsingularity Assumption." Computing (Vienna/New York) 74(1):23-39.
Fan, Jinyan and Jianyu Pan. 2009. "A Note on the Levenberg - Marquardt Parameter Q." Applied Mathematics and Computation 207(2):351-59. Retrieved (http://dx.doi.org/10.1016/j.amc.2008.10.056).

Hakim, R. B.Fajriya, Eka Novita Sari, and Tutut Herawan. 2014. "Soft Solution of Soft Set Theory for Recommendation in Decision Making." Advances in Intelligent Systems and Computing 287:313-24.

Hamet, Pavel and Johanne Tremblay. 2017. "Artificial Intelligence in Medicine." Metabolism: Clinical and Experimental 1-14. Retrieved (http://dx.doi.org/10.1016/j.metabol.2017.01.0 $11)$.

Hrasko, Rafael, André G. C. Pacheco, and Renato A. Krohling. 2015. “Time Series Prediction Using Restricted Boltzmann Machines and Backpropagation." Procedia Computer Science 55:990-99. Retrieved (http://linkinghub.elsevier.com/retrieve/pii/S1 877050915015793).

Khanesar, Mojtaba Ahmadieh and Erdal Kayacan. 2013. "Levenberg-Marquardt Training Method for Type-2 Fuzzy Neural Networks and Its Stability Analysis." IEEE International Conference on Fuzzy Systems 1-7.

Lasisi, Ayodele, Rozaida Ghazali, and Tutut Herawan. 2014. "Comparative Performance Analysis of Negative Selection Algorithm with Immune and Classification Algorithms." Advances in Intelligent Systems and Computing 287:441-52. Retrieved (http://link.springer.com/10.1007/978-3-31907692-8_42).

Levenberg, Kenneth. 1944. "A Method for the Solution of Certain Non-Linear Problems in Least." Quarterly of Applied Mathematics 2(278):164-68. Retrieved (http://www.ams.org/qam/1944-02-02/S0033569X-1944-106660/\%0Ahttp://www.ams.org/journals/qam/1944 -02-02/S0033-569X-1944-10666-0/S0033569X-1944-10666-0.pdf).

Marquardt, Donald W. 1963. “An Algorithm for Least-Squares Estimation of Nonlinear Parameters." Journal of the Society for Industrial and Applied Mathematics 11(2):431-41. Retrieved (http://epubs.siam.org/doi/10.1137/0111030).

Mishra, Akash, Pravin Chandra, Udayan Ghose, and Sartaj Singh Sodhi. 2017. "Bi-Modal Derivative Adaptive Activation Function 
Sigmoidal Feedforward Artificial Neural Networks." Applied Soft Computing Journal 61:1-27.

Retrieved (http://dx.doi.org/10.1016/j.asoc.2017.09.002).

Parveen, Nusrat, Sadaf Zaidi, and Mohammad Danish. 2017. "Development of SVR-Based Model and Comparative Analysis with MLR and ANN Models for Predicting The Sorption Capacity of Cr(VI)." Process Safety and Environmental Protection 107(6):428-37. Retrieved (http://dx.doi.org/10.1016/j.psep.2017.03.007).

Putra Siregar, Sandy and Anjar Wanto. 2017. "Analysis Accuracy of Artificial Neural Network Using Backpropagation Algorithm In Predicting Process (Forecasting)." International Journal Of Information System \& Technology 1(1):34-42.

Salimifard, Maryam and Ali Akbar Safavi. 2013. "Nonlinear System Identification Based on a Novel Adaptive Fuzzy Wavelet Neural Network." Conference: Electrical Engineering (ICEE) 1-5.

Sarabakha, Andriy, Nursultan Imanberdiyev, Erdal Kayacan, Mojtaba Ahmadieh Khanesar, and Hani Hagras. 2017. "Novel LevenbergMarquardt Based Learning Algorithm for Unmanned Aerial Vehicles." Information Sciences 1-32. Retrieved (http://dx.doi.org/10.1016/j.ins.2017.07.020).

Sumijan, Agus Perdana Windarto, Abulwafa Muhammad, and Budiharjo. 2016. "Implementation of Neural Networks in Predicting the Understanding Level of Students Subject." International Journal of Software Engineering and Its Applications 10(10):189-204.

Retrieved (http://dx.doi.org/10.14257/ijseia.2016.10.10.1 8).

Tesfaselassie, Mewael F. and Maik H. Wolters. 2017. "The Impact of Growth on Unemployment in a Low vs. a High Inflation Environment." Review of Economic Dynamics (July):1-33.

Retrieved (http://dx.doi.org/10.1016/j.red.2017.07.005).

Wang, Zhen-Hua, Dian-Yao Gong, Xu Li, GuangTao Li, and Dian-Hua Zhang. 2017. "Prediction of Bending Force in The Hot Strip Rolling Process Using Artificial Neural Network and Genetic Algorithm (ANN-GA)." The International Journal of Advanced Manufacturing Technology 1-14.

Wanto, A., M. Zarlis, Sawaluddin, and D. Hartama. 2017. "Analysis of Artificial Neural Network
Backpropagation Using Conjugate Gradient Fletcher Reeves in the Predicting Process." Journal of Physics: Conference Series 930(1):1-7.

Wanto, Anjar, Agus Perdana Windarto, Dedy Hartama, and Iin Parlina. 2017. "Use of Binary Sigmoid Function And Linear Identity In Artificial Neural Networks For Forecasting Population Density." International Journal Of Information System \& Technology 1(1):43-54.

Yamashita, N. and M. Fukushima. 2001. "On the Rate of Convergence of Levenberg-Marquardt Method." Computing Supplementa 15:239-49.

Yunong Zhang and Ke Chen. 2008. "Comparison on Zhang Neural Network and Gradient Neural Network for Time-VaryingLinear Matrix Equation AXB = C Solving." 2008 IEEE International Conference on Industrial Technology 1-6. Retrieved (http://ieeexplore.ieee.org/lpdocs/epic03/wrap per.htm?arnumber=4608579).

Zhang, Qiang, Xian ku Zhang, and Nam kyun Im. 2017. "Ship Nonlinear-Feedback Course Keeping Algorithm Based on MMG Model Driven by Bipolar Sigmoid Function for Berthing." International Journal of Naval Architecture and Ocean Engineering 9(5):525-36. Retrieved (http://dx.doi.org/10.1016/j.ijnaoe.2017.01.004 ). 